\title{
Short Experimental Ceramic Projects to Incentivise Mechanical Engineering Students
}

\author{
http://dx.doi.org/10.3991/ijep.v2i2.2088 \\ J. Lino, T. P. Duarte \\ Universidade do Porto, Portugal
}

\begin{abstract}
Considerable efforts of the teaching community have been directed to capture students' attention during university classes. It is well known that when students enter University they are extremely familiar with all the informatics tools, specially, finding information on the World Wide Web and doing funny power point presentations. Although this is a good tool for the first rapid knowledge and communication, a deeper study is always required. Considering students' low sensitivity to technological problems due to their immaturity, introducing methodologies to capture their concentration and motivation to learn is a key factor for the development of fundamental competences. After many years of teaching a course about ceramics, polymers and composite materials in the Integrated Master in Mechanical Engineering of the Faculty of Engineering of the University of Porto, Portugal, the authors seek to continuously introduce project based learning methodologies to improve their students' grades and competences. One of the main innovations introduced in recent years and emphasized in the academic year of 2011/12 is a practical work (short project) that uses all the experimental facilities available at FEUP and INEGI (research institute in mechanical engineering field, located on the FEUP campus). With this experimental project, the students' enrolment was enhanced with a better knowledge about the ceramics subject and the skills related to the CDIO (Conceive-Design-ImplementOperate) competences.
\end{abstract}

Index Terms-Engineering education, mechanical engineers; ceramic materials; project based learning.

\section{INTRODUCTION}

Nowadays, the World Wide Web (www) is a common established tool for students searching information about the subjects taught in the different university courses. Although this is a good tool for the first rapid knowledge, a deeper study is usually required to better understand the scientific principles related tothe broad variety of subjects. Furthermore, there is a tendency, due to the high number of students admitted to the first years, to reduce the number of experimental works, and considering that due to the rate of life of our "digital society", students' experimental skills and sensibility of "how to do it" are strongly reduced, despite the contribution of the www as a possible medium for discussion and interaction, the reinforcement of the experimental activities is strongly recommended.

This is the main deficiency that the authors detected on their mechanical engineering students during their part of classes about ceramic materials (third year, first semester). Since 2006, different approaches have been introduced in the course to increase the students' motivation and assimilation of the topics covered on the ceramic classes [1].
In general, the main concerns of the mechanical engineering professors [2] are the transmission of tools for the development of the general competences (CDIO) [3] and scientific knowledge, and also the development of the present society demanded skills that will be very helpful in the future active professional life.

In the ceramic classes, the scientific knowledge is transmitted through videos, experimental work and technical visits to ceramic manufacturing companies [1]. Bravo et al. [4] also emphasise the importance of this type of classes, namely the introduction of videos.

One of the main innovations introduced in 2011 is experimental work that comprises the project of a small ceramic component or the use of ceramic materials to obtain a final part in different types of materials, using the manufacturing processes available in the Campus. This type of work was already used in the past, but not with clear rules and continuous supervision of technicians, engineers and teachers.

Students (in groups of 2) have to design a component, using a 3D software (usually SolidWorks), produce a prototype by manual moulding or additive manufacturing (Rapid Prototyping), namely the stereolithography process (the one that is available in our laboratories), and use different direct or indirect conversion technologies to produce the final part. They can also propose their own topics, or use other approaches to obtain a final product.

With this experimental work and the other evaluation components, as it will be explained afterwards, students enrolment in the classes and their self-study was enhanced, with a significant improvement in the knowledge about the ceramics subject, skills related to innovation capacity and initiative to experimentation and research to solve problems, and consecutively on the final grades.

The Faculty of Engineering of University of Porto (FEUP), Portugal, has the Integrated Master Course in Mechanical Engineering (MIEM, 5 years course) that obtained the EUR-ACE Accreditation of European Engineering Programs in 2008. This course has a considerable incidence in materials and technological processes. The introduction of these subjects with the detail that is presently taught is related to the type of mechanical engineers' necessities of the region and the country industrial tissue, and the global employment market.

The curricular unit of Materials II [5], of the third year of MIEM, first semester, is divided in two main subjects; i) study of ceramic materials, and ii) study of polymers and composites of polymeric matrix. The authors of this work are in charge of teaching the part of ceramic materials, which approximately represents $40 \%$ the course (10 
PAPER

SHORT Experimental Ceramic Projects to InCENTIVISE MECHANICAL ENGINEERING StUdents

classes of $2 \mathrm{~h}$ each, in a total of 28 classes per semester of 14 weeks).

In the past, before 2006, teaching was performed in the classic way, with theoretical and practical classes. In the theoretical classes ( 8 classes of 1 hour in a total of 24 per semester of 12 weeks, for around 130 students at the same time, where it was impossible to have a personalized knowledge about each student), and considering the short number of classes to teach the subject "ceramics", the emphasis was put on clarifying the differences between traditional and technical ceramics. A short introduction to the sintering process and explanation of the main differences between solid state and liquid phase sintering, and relating them with the final mechanical properties of the ceramic products was also addressed. After this, students had a short introduction to the manufacturing processes and mechanical properties, with special emphasis on toughness and current research that has been conducted to improve these properties, in order to be able to increase the penetration of ceramics in the materials world applications. Harmer, Chan and Miller [6] wrote an excellent paper about these challenging opportunities. More recently, with the popularity of "Sushi" (Japanese food) in Portugal that for which preparation ceramic zirconia blades are used, the curiosity about this group of materials and respective toughness is even more enhanced.

In the ceramics' practical classes ( $2 \mathrm{~h}$ per week for 4 weeks, in a total of 12 weeks, for 25 students, maximum) students had the opportunity to carry on simple experiments, namely press powders, determine densities and the respective level of porosity and finally evaluate the effect of sintering on the mechanical resistance of the samples and microstructural changes.

The final grade was divided in $20 \%$ for the reports of practical classes and the remaining $80 \%$ for the final exam.

In 2006, when the course was approved by Bologna Process, the classes were changed to just practical ones (with 4 works for ceramics and 3 for polymers) to achieve the CDIO and EUR-ACE competences (see Course Goals). The goal was to give the student a more responsible and proactive attitude, which is characterized by spending much more time at university/home studying the main topics taught in classes. Although the contents of the course remain the same, at the beginning of some classes each subject is briefly presented for $15-20$ minutes maximum. After that, students have to answer the questions on the practical works using class facilities and complementary work done at university/home (the course has 6 ECTS - European Credit Transfer and Accumulation System [7], where 1 ECTS corresponds to 27h work).

After 2008, 2 reports for each part: ceramics and polymers, and answers to some handouts to be solved in class or at home are the only itemsresponsible for the final grade obtained. This means that a deeper knowledge has to be acquired about the students from the discussions in all practical classes and the continuous contact with the teacher, to obtain a more accurate and fair assessment.

This type of evaluation (PBL - Project Based Learning), in cooperation with several companies, also started to be implemented in 2010/11, with a great success, in FEUP, in the Specialization Course in Design and Product Development (EDDP) [8, 9].
Panthalookaran and Binu [10], in Rajagiri School of Engineering and Technology, India, also tried something similar to nurture general management skills in their engineering students. Kostal, Mudrikova and Caganova [11], in Slovak University of Technology, Slovak Republic, improved their teaching methodologies through virtual laboratories, enforcing students' capacities to learn by their self-activity and self-responsibility and improving their communication skills. Martinez, Romero, Marquez and Perez [12] in Polytechnic University of Madrid promoted the PBL in their Mechanical/Industrial Engineering courses. Frank, Lavy and Elata [13], in Technion, Israel, implemented the PBL through mini-projects that require the design and construction of devices that perform predefined tasks.Meanwhile, some of our Department colleagues have also been doing great efforts to introduce these types of methodologies in their classes.

Many other present publications [4, 14, 15] claim the importance of the PBL for a more effective knowledge transmission, which encourages extra efforts to keep improving and innovating in teaching methodologies in our ceramics/polymers course.

\section{A. Course Goals}

By the end of the semester, students are expected to have acquired basic and advanced knowledge in the field of ceramic materials, polymers and composites of polymeric matrix, namely:

a) Knowledge of the different ceramic materials, polymers and composites of polymeric matrix used in different branches of engineering, their main applications and properties;

b) Comprehension about the mechanical properties of these materials;

c) Capacities to perform different types of experimental work, collect data, interpret and relate them to the different subjectscovered. Perform small projects involving the materials taught; namely materials and manufacturing processes selection;

d) Capacities to collect scientific data using different sources (books, scientific papers, databases, internet, technical visits and public oral discussions);

e) Capacity to perform practical group works, presentation and discussion of the resultsachieved.

The ceramics part of the course should contribute to the EUR-ACE skills [16] which for this course are (summary):

a) 3.1 - Knowledge and understanding - An in-depth knowledge and understanding of the principles of their branch of engineering;

b) 3.2 - Engineering analysis - The ability to solve problems that are unfamiliar, incompletely defined, and have competing specifications;

c) 3.3 - Engineering design - The ability to use their engineering judgment to work with complexity, technical uncertainty and incomplete information;

d) 3.4 - Investigations - The ability to identify, locate and obtain required data; 
e) 3.6 - Transferable skills - Work and communicate effectively in national and international contexts;

and contribute to the following CDIO (ConceiveDesign-Implement-Operate) skills number [3]:

a) 1.2 (nuclear knowledge in engineering);

b) 1.3 (advanced knowledge in engineering);

c) 2.1 (thinking and resolution of engineering problems);

d) 2.2 (experimentation and knowledge discovering);

e) 2.4 (personal skills and attitudes);

f) 3.1 (group work);

g) 3.2 (communication);

h) 4.4 (project).

In this paper emphasis is given to the Practical Work number 2 "Project and manufacturing of a ceramic component", which corresponds to $45 \%$ of the final grade of the ceramics part of the course (45\% for the first work [1] and $10 \%$ for handouts). In alternative students can do another work related to pressing a powder, sintering a sample, determining the densification curve, microstructure evolution and answering several questions related to fracture toughness and R-curve behaviour, and manufacturing processes.

In this type of work, they should be able to:

- Study a course content using bibliographic review and write a report about it;

- Perform experimental work, describe it, obtain results and discuss them;

- Do team work; write reports, presentations and deal with conflicts.

\section{Methodology}

The goal of this practical work (small project) is that the students group (2 elements) manufacture a product using ceramic materials and simple manufacturing processes. Special care should be addressed to the following factors: literature review; specification of all the work stages, including design, project, materials, equipment, processes, applications, mechanical, thermal and other relevant properties; results and discussion; conclusions and future work.

Type of projects suggested:

a) Project and manufacture of a clay or a plaster part;

b) Study and development of a manufacturing process to produce porous parts in a ceramic material (include lost polystyrene spheres or others);

c) Manufacture of a wax sculpture. Production of a ceramic shell, dewaxing and casting of a metallic alloy;

d) Auto CAD modelling of a part, generate the STL file and respective additive manufacturing model (by stereolithography), place it in a moulding box and cast plaster/ceramic slurry. Cast a low melting point alloy;

e) Manufacture ceramic parts using silicone moulds; f) Use fusing technique to produce artistic glass parts;

g) Characterization (materialographic techniques and mechanical tests) of a ceramic component used in an insulator.

Each group should submit a printed and digital report (this should include all the complementary information obtained during the project) developed till the deadline.

\section{PROJECTS}

As explained before, students that chose a project from all theavailable proposals, started to work when the practical work number 2 was delivered, but for this project, they had more time than the other students that selected the other work. They had to deliver the final report just at the end of the semester due to the amount of work and uncertainty associated to this type of experimental work.

In order to give an idea of the type of work developed, several examples of the final products produced in the past are presented, where this methodology was tested with several groups, and it is described in detail a project of the academic year of 2011/12.

Figs. 1 to 6 show different final products obtained in 2006/07. Fig. 1 presents an ashtray made by glass thermoforming and fusing technique where the glass is placed on a ceramic mold to acquire the ceramic mold shape and get the fusion of the different colored glasses placed over the transparent glass (this technique is described in $[17,18]$ ). Fig. 2 presents a wall clock also obtained by this glass fusing $\left(820^{\circ} \mathrm{C}\right)$ process. Fig. 3 shows a metallic gear obtained by casting an aluminium alloy in a ceramic block moulding consolidated by the gel casting process (more details about this process can be obtained in [19, 20]). The gear was modeled in SolidWorks, to produce an acrylic (PMMA) model (laser cut) that was placed in a box to cast the ceramic slurry which after burning the alcohol and sintered at $1050^{\circ} \mathrm{C}$ for $2 \mathrm{~h}$ was used as a mould to cast, at $730^{\circ} \mathrm{C}$, a duraluminium alloy. The sculpture of Fig. 4 was made with clay, which is a traditional ceramic that was hand molded and fired at $920^{\circ} \mathrm{C}$ in a furnace to achieve the final strength (details of this manufacturing process are indicated in [21]). Fig. 5 is a decorative ceramic part of FEUP logo. Fig. 6 exhibits an airplane obtained by the investment casting process and presents the main stages to reach the final metallic part for tests in a wind tunnel; CAD 3D modeling of the part, manufacturing a lost model in quick cast (hollow stereolithography), production of the ceramic shell, cast the metallic alloy and finish the part.

For 2011/12, a group decided to choose a project that seeks to produce a commemorative metallic plate referring the department of mechanical engineering (DEMec), the course of MCM II, and the Faculty of Engineering (FEUP). These students designed the part considering a small draft angle to allow the demolding of the prototype. Fig. 7 shows the 3D CAD file, designed with the SolidWorks program. Then, a STL file was exported to the stereolithography machine (Viper SI, from 3D Systems, USA), to manufacture an epoxy resin prototype (SL) (Fig. 7 , right side). 
PAPER

SHORT Experimental Ceramic Projects to InCENTIVISE MECHANICAL ENGINEERING StUdents

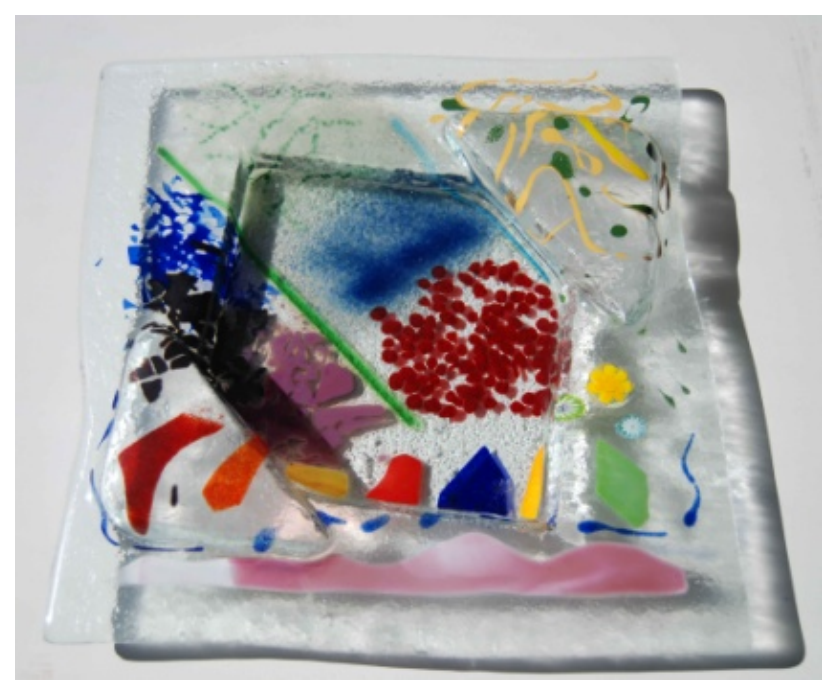

Figure 1. Glass thermoforming and fusing technique to manufacture an ashtray.

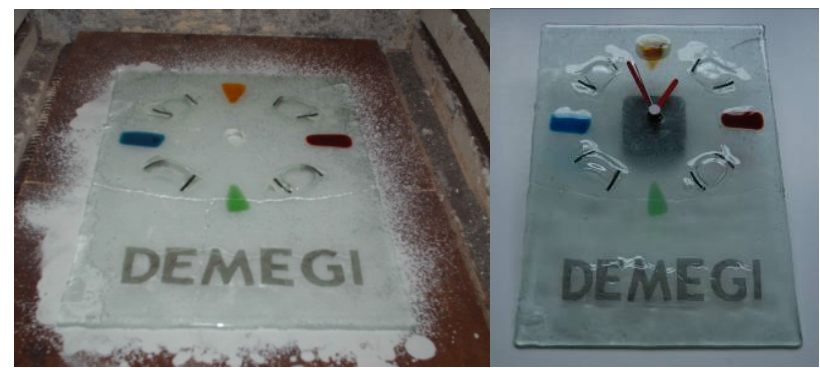

Figure 2. Glass fusing technique to manufacture a wall clock. The white powder is a demolding agent (boron nitride).
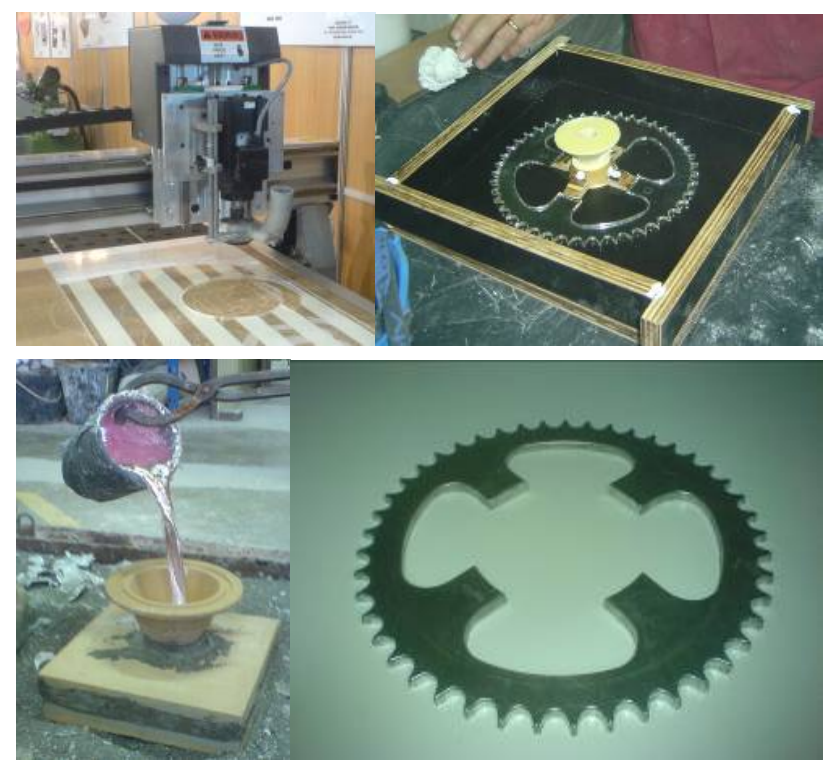

Figure 3. Ceramic block moulding to cast a duraluminium gear.

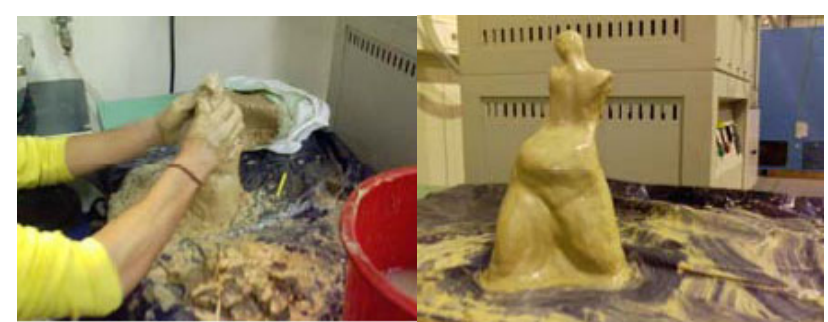

Figure 4. Clay sculpture.

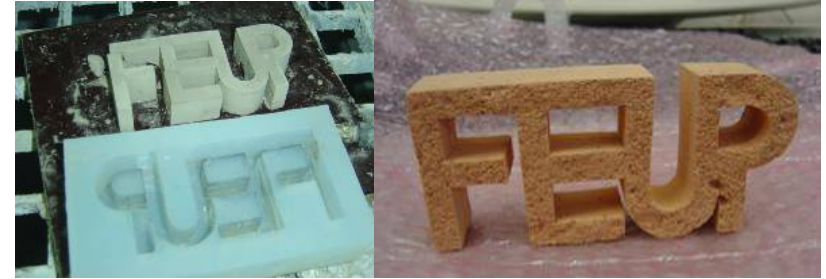

Figure 5. Silicone mould and decorative ceramic part cast on it.
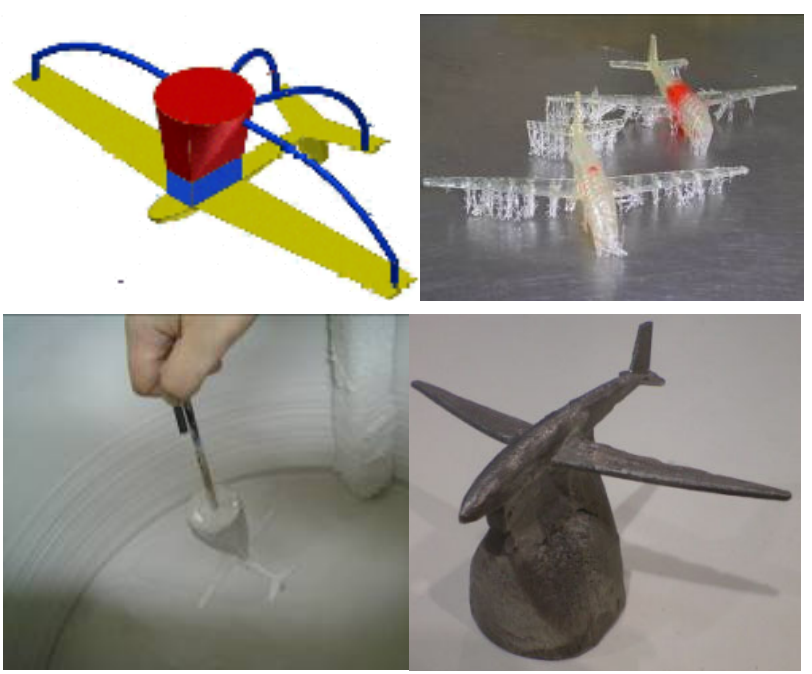

Figure 6. Metallic airplane for tests in a wind tunnel; CAD model, quick cast model, ceramic shell manufacturing and metallic casted part.

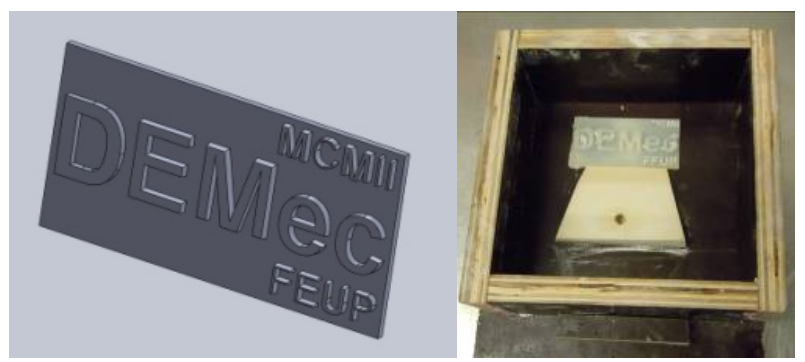

Figure 7. Image of the metallic plate to be obtained and SL prototype with the gating system.

After cleaning and post-cure in a UV furnace, the prototype was placed in a wooden box to cast a ceramic slurry (1400 gr of zircon; 30\% 100mesh, 30\% 325mesh and $40 \%$ 200mesh, 200ml hydrolysed tetraethoxysilane, and $6 \%$ of catalyst - ammonium hydroxide) (Figs. 7 and 8). The first tests demonstrated that students were not able to remove the ceramic mould without defects due to: chemical reaction with the resin of the prototype; small draft angles, surface roughness (due to SL process) and small size of the letters in the names "DEMec" and "FEUP".

The part had to be redesigned to increase the plate size and change the experimental procedure. After these changes an adequate mould for casting the metallic alloy was obtained. The experimental sequence was now:

- Redesign the plate and model production (Fig. 9);

- Cast a silicone (T4, Dow Corning, USA, 24h cure, and post-cure for $1 \mathrm{~h}$ at $70^{\circ} \mathrm{C}$ ) mould (Fig. 9);

- Cast the ceramic slurry on the silicone mould and demolding after 10 minutes (Fig. 10).This procedure avoids the contact of the ceramic with the resin model, 
PAPER

SHORT Experimental Ceramic Projects to InCENTIVISE MECHANICAL ENGINEERING StUdents

and consequently the reaction occurred in the previous try. This is a critical step because the ceramic cannot have air bubbles on the interface with the silicone. Sintering the ceramic mould (heating rate: $1000^{\circ} \mathrm{C} / \mathrm{h}, 2 \mathrm{~h}$ at $1000^{\circ} \mathrm{C}$ and cooling into the furnace);

- Heat at $120^{\circ} \mathrm{C}$ a low melting point alloy $\left(95^{\circ} \mathrm{C}\right.$ melting temperature, composed by $52.5 \% \mathrm{Bi}, 32 \% \mathrm{~Pb}$, and $15.5 \% \mathrm{Sn})$. Pre-heat the ceramic mould at $70^{\circ} \mathrm{C}$ and cast at $107^{\circ} \mathrm{C}$ the metallic alloy (Fig. 11);

- Finish the part and exhibition (Fig. 11).

This project used this sequence because the goal was to obtain just one part. If more parts were demanded one could use a wax injection $\left(70^{\circ} \mathrm{C}\right)$ into a silicone mould to obtain several "lost" prototypes. These prototypes, after degreasing, are assembled in a wax structure (wax models with the gating and rising system) for investment casting. The shells were then manufactured using 2 slurry layers and several layers slurry/sand, in a total of 8 ceramic layers. The shells are dewaxed for $1 \mathrm{~h}$ at $1050^{\circ} \mathrm{C}$ and sintered at $1200^{\circ} \mathrm{C}$. Ceramic shells are then pre-heated at $250^{\circ} \mathrm{C}$ for 1 hour, to reduce the thermal shock and assure an easier metal filling during the casting of an aluminium alloy (or other metal). After casting an aluminium alloy (EN 132/100-1992 AlSi9Cu3) at $720^{\circ} \mathrm{C}$, into the ceramic shell cavity, shaking out, cleaning the metallic parts with a high pressure (500 bar) water pistol and cutting of the feeding system and the risers, and minor surface finishing operations, the part is ready to be used Fig. 12 shows a scheme containing all these stages.

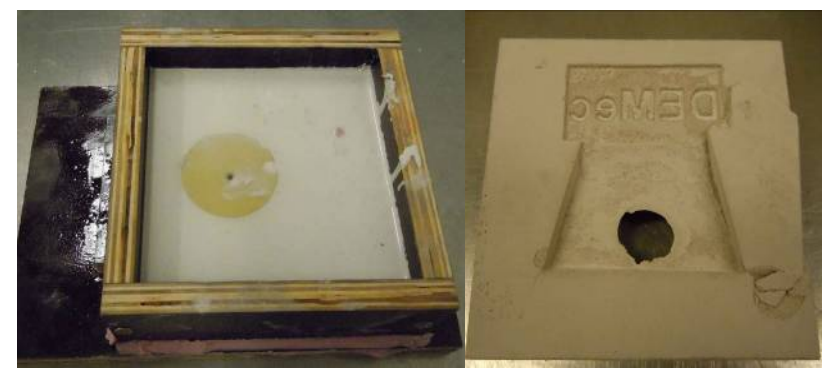

Figure 8. Box containing the model with the gating system and the slurry, and final ceramic mould with defects.

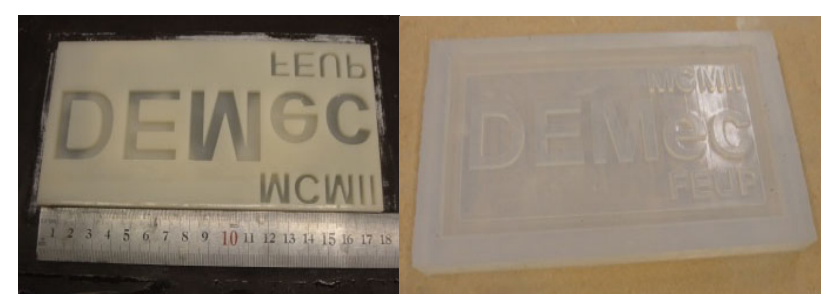

Figure 9. Stereolithography model and silicon mould.

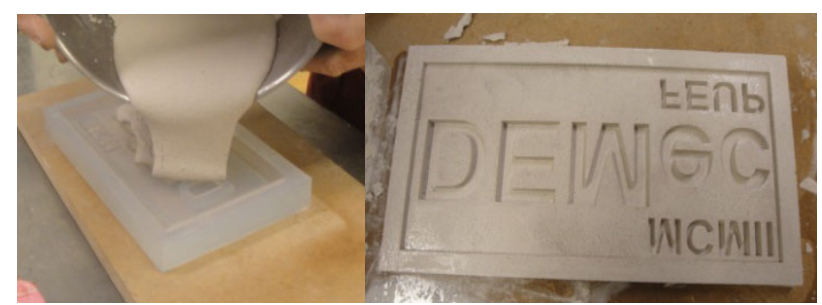

Figure 10. Casting the ceramic slurry and final ceramic mould.
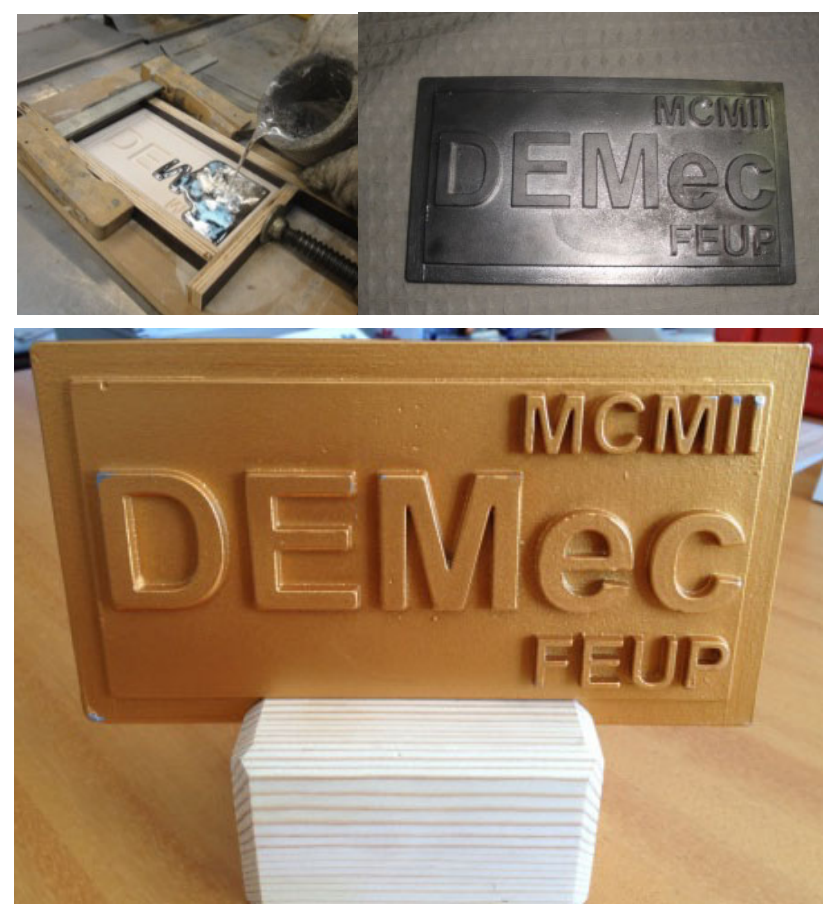

Figure 11. Casting the low melting point alloy and final part.

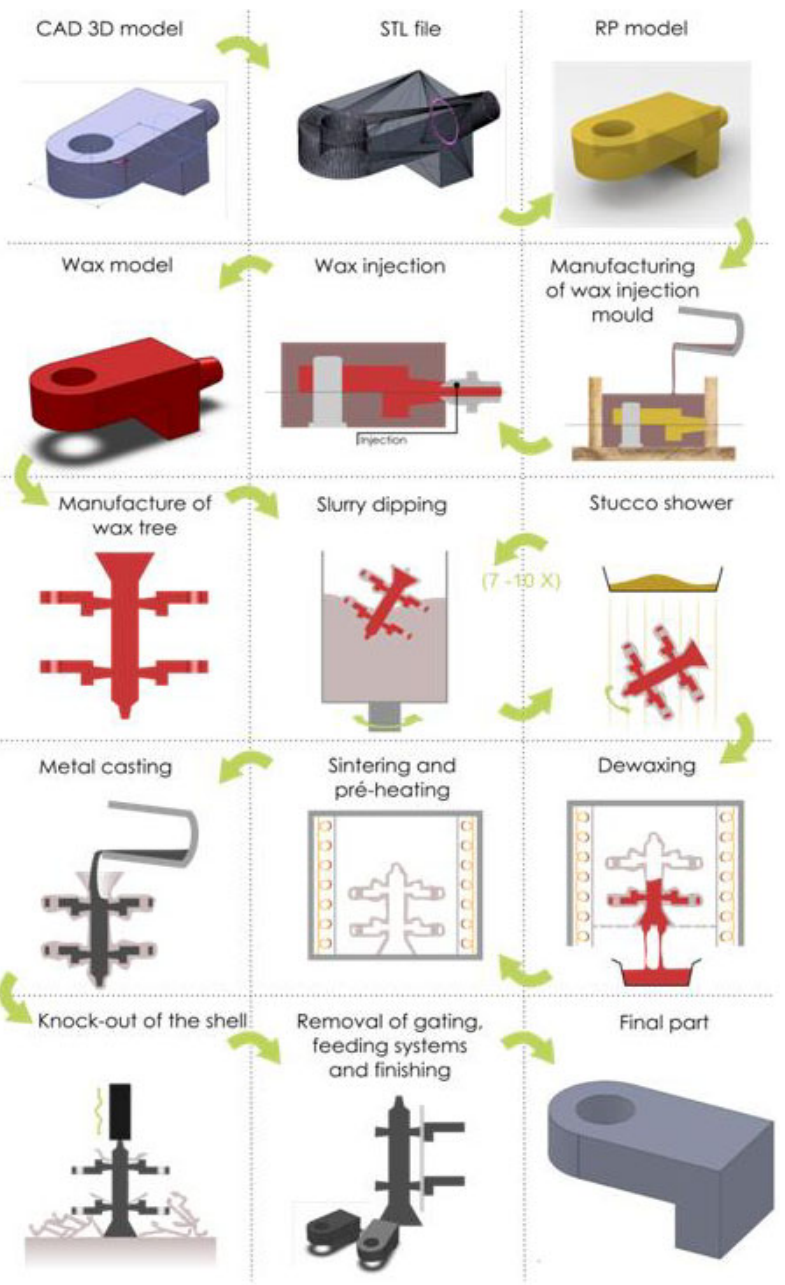

Figure 12. Manufacturing sequence to produce a metallic part using the investment casting process. 


\section{RESULTS}

Fig. 13 shows the percentage of approved students from the academic year of 2005/06 until the present.

The graph reveals that the change from the classic grading evaluation (done with the theoretical classical exam 2005/2006) to the present one (started in 2006/2007) improved the motivation for the curricular unit, resulting in a larger number of approved students (just considering the students that were submitted to all the evaluation procedure). We know that this type of evaluation favours students with lower performance, but creating more moments of evaluation could contribute to a better distinction.

It should be also referred that the slight decrease in $2009 / 10$ is due to the fact that a more rigorous control of classes' participation and assiduity gave the capacity to distinguish students. In 2010/11 the number of approved students increased again because students know already that we are extremely rigorous in controlling all the evaluation phases (for instance a student that misses one class where a part of the work is done has " 0 " value for that specific part) [22].

Fig. 14 shows the average final grade. This graph also presents an improvement on the average grades in the last four academic years. We are convinced that the value obtained in 2010/11 is due to the clear rules of how the curricular unit works and the specific classes that they had in information literacy, electronic microscopy analysis and how to use the software for materials and processes selection (CES EDUPACK 2010) [23, 24]. In 2011/12 two new professors were admitted for the polymers part, and they were more generous in terms of grades.

\section{CONCLUSIONS}

The introduction of continuous evaluation in the course of Materials II of the Integrated Masters in Mechanical Engineering of the Faculty of Engineering of the University of Porto changed, with success, the way students study the ceramics, polymers and composites materials subjects.

It was demonstrated that the evaluation of the students with practical works followed by the elaboration of reports, although very intensive and effort demanding, are something that they enjoy and actively participate. This structure facilitates their learning and enrolment, increasing their knowledge about the topics covered on the course and contributes to the improvement of their research and synthesis capacities and experimental skills that they will constantly need in the near future.

Although this paper presents the work developed in the ceramics part, the same was adopted in the polymers and composites subject.

This type of projects has several benefits to the students and contributes to improve their soft skills, namely: work with project tools; the necessity to relate the knowledge obtained in different curricular units, such as drawing, materials, manufacturing processes, fluids mechanics, mechanical properties, etc.; deal with success and unsuccess related to experimental research (which does not always goes as forecasted); develop critical spirit, and experimental initiative (do it yourself); work in teams, deal with technicians, engineers and other players and feel the dificulties and search for ways to overcome them.
\% Approved Students

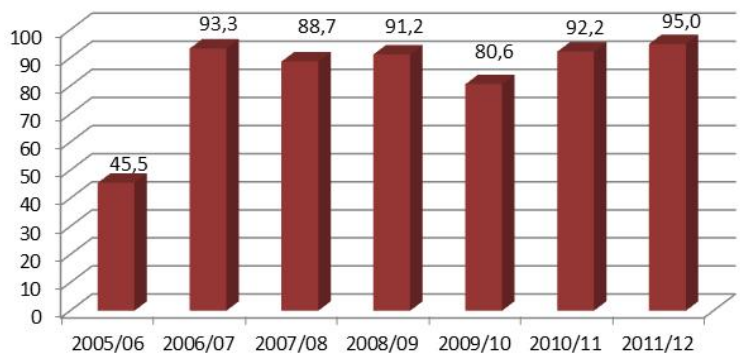

Figure 13. Percentage of approved students throughout the latest7 academic years.

\section{Average Classification}

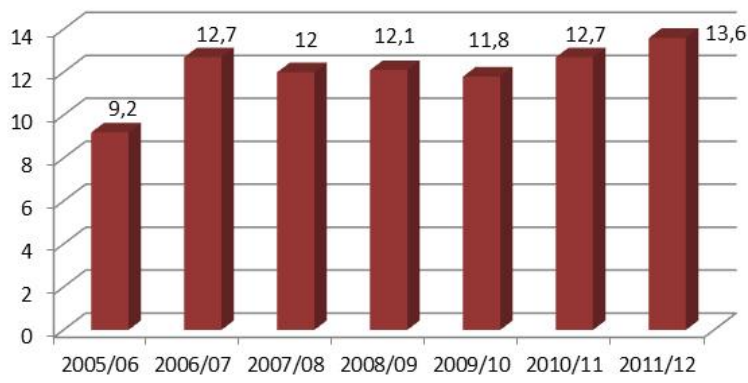

Figure 14. Average classification (out of 20) along the latestseven academic years.

The authors are extremely convinced that these competences will be extremely important for their future as engineers in a global market. Ideally, this experience and results obtained should encourage other professors to try something similar in their curricular units.

\section{ACKNOWLEDGMENT}

To J. Santos, M. Assunção, M. Martins, I. Pereira, R. Neves, T. Lima, F. Reis, V. Gomes, S. Rocha and T. Serrado, for their images and motivation.

\section{REFERENCES}

[1] F.J. Lino and T.P. Duarte, "Research skill enhancement in future Mechanical engineers”, International J. Eng. Pedagogy 1, 1, pp. 20-26, 2011.

[2] K. Henning, G. Bornefeld, and S. Brall, "Mechanical engineering at RWTH Aachen University: professional curriculum development and teacher training”, Europ. J. Eng. Education, vol. 32 (4), pp. 387-399, 2007. http://dx.doi.org/10.1080/03043790701333584

[3] http://www.cdio.org, accessed July 2011.

[4] E. Bravo, B. Amante, P. Simo, M. Enache, V. Fernandez, "Video as a new teaching tool to increase student motivation", 2011 IEEE Global Engineering Education Conference (EDUCON) - "Learning Environments and Ecosystems in Engineering Education", April 4 - 6, 2010, Amman, Jordan, pp. 638 - 642

[5] www.fe.up.pt/si uk/DISCIPLINAS GERAL.FORMVIEW?P CA D_CODIGO=EM0027\&P_ANO_LECTIVO=2011/2012\&P_PERI ODO $=1 \mathrm{~S}$ (accessed in November 2011).

[6] M. Harmer, H. Chan, and G. Miller, "Unique opportunities for microstructural engineering with duplex and laminar composites", J. Am. Ceram. Soc., 75 (7), pp. 1715-1728, 1992. http://dx.doi.org/10.1111/j.1151-2916.1992.tb07188.x

[7] http://ec.europa.eu/education/lifelong-learningpolicy/doc48 en.htm, accessed December 2010. 
PAPER

[8] C. Aguiar, and X. Carvalho, "Design e desenvolvimento de produto: aprendizagembaseadaemprojectos (PBL Project Based Learning)”, Tecnometal [188], pp. 26-32, MaioJunho 2010 (in portuguese).

[9] Carlos Aguiar, Jorge Lino, Xavier Carvalho, António Torres Marques, "O ensino do design industrial baseadoemprojecto e naintersecção das culturas da engenharia e da gestão”, $6^{\circ}$ CongressoLuso-Moçambicano de Engenharia, Maputo, Moçambique, 29 August-2 September 2011 (in portuguese).

[10] V. Panthalookaran and R. Binu, "Some models and methods to nurture general management skills in engineering students living in large residential communities”, ESDA 2010 - ASME 2010 10th Biennial Conference on Engineering Systems Design and Analysis, session on Science, Engineering and Education, Istanbul, Turkey, July 12-14, 2010.

[11] P. Kostal, A. Mudrikova and D. Caganova, "The virtual laboratory of program control”, ESDA 2010 - ASME 2010 10th Biennial Conference on Engineering Systems Design and Analysis, session on Science, Engineering and Education, Istanbul, Turkey, July 1214, 2010.

[12] M. Martinez, G. Romero, J. Marquez, and J. Perez, "Integrating teams in multidisciplinary project based learning in mechanical engineering”, IEEE EDUCON Engineering 2010 - The Future of Global Learning Engineering Education, April 14-16, Madrid, Spain, 2010.

[13] M. Frank, I. Lavy, and D. Elata, "Implementing the project -based learning approach in an academic engineering course”, Int. J. Techn. Design Educ. [13], pp. 273-288, 2003.

[14] C.G. Pérez, P.M. García, J.S. López, "Project-based learning experience on data structures course”, 2011 IEEE Global Engineering Education Conference (EDUCON) - "Learning Environments and Ecosystems in Engineering Education" April 4 - 6, 2010, Amman, Jordan, pp. 561-566.

[15] Z. Zhou, "Work in progress - project-based learning in manufacturing process", $4^{\text {th }}$ ASEE/IEEE frontiers in education conference, session T1J-1-2, Washington DC, October 27-30, 2010.

[16] http://www.engc.org.uk/education--skills/accreditation/europeanaccreditation.aspx, accessed December 2010.

[17] P. Beveridge, IgnasiDoménech and E. PAscual, “O vidro -técnicas de trabalho de forno”, Editorial Estampa, 2004.
[18] R. Thompson, "Manufacturing processes for design professionals”, Thames \& Hudson, 2007.

[19] T.P. Duarte, F.J. Lino, A.B. Magalhães R.J. Neto and J.M. Ferreira, "Conversion of rapid prototyping models into metallic tools by ceramic moulding - an indirect rapid tooling process”, International Journal of Materials and Product Technology, Vol. 21 No4, pp. 317-330, 2004.

[20] F. Jorge Lino, Pedro Ala, Rui J. L. Neto, Bártolo Paiva, Ricardo Paiva and Rui Sousa, "Indirect rapid tooling with investment casting and ceramic moulding”, Proceedings of VRAP 2003, 1st International Conference on Advanced Research in Virtual and Rapid Prototyping, pp. 517-24, Published by Escola Superior de Tecnologia e Gestão de Leiria, Portugal, 1-4 October 2003.

[21] J. Vigué and J. Chavarria, “A cerâmica - a técnica e a arte da cerâmicaexplicadas de modomais simples e atraente”, Colecçãoartes e ofícios, Editorial Estampa, 1997.

[22] F.J. Lino, and T. Duarte, "Development of competitive skills in future mechanical engineers”, ESDA 2010 - ASME 2010 10th Biennial Conference on Engineering Systems Design and Analysis, session on Science, Engineering and Education, Istanbul, Turkey, July 12-14, 2010.

[23] F.J. Lino, and T. Duarte, , "EM0027 Materiais de construçãomecânica II”, Jornada de PartilhaPedagógica, Laboratório de Ensino e Aprendizagem (LEA), FEUP, 14 de Julho de 2010 (in portuguese).

[24] http://www.grantadesign.com, accessed November 2011.

\section{AUTHORS}

J. Lino is with the Department of Mechanical Engineering of the Faculty of Engineering of the University of Porto, Portugal, and belongs to the Research Unit INEGI (e-mail: falves@fe.up.pt).

T.P. Duarte, is with the Department of Mechanical Engineering of the Faculty of Engineering of the University of Porto, Portugal, and belongs to the Research Unit INEGI (e-mail: tpd@fe.up.pt).

This article is an extended version of a paper presented at the International Conference IEEE EDUCON2012, held in April 2012, in Marrakesh, Morocco. Received, 22 April 2012. Published as resubmitted by the authors 30 April 2012 